\title{
An assessment of producer precision dairy farming technology use, prepurchase considerations, and usefulness
}

\author{
M. R. Borchers and J. M. Bewley ${ }^{1}$ \\ Department of Animal and Food Sciences, University of Kentucky, Lexington 40546
}

\begin{abstract}
An online survey to identify producer precision dairy farming technology perception was distributed in March 2013 through web links sent to dairy producers through written publications and e-mail. Responses were collected in May 2013 and 109 surveys were used in statistical analysis. Producers were asked to select parameters monitored by technologies on their farm from a predetermined list and $68.8 \%$ of respondents indicated technology use on their dairies (31.2\% of producers not using technologies). Daily milk yield $(52.3 \%)$, cow activity $(41.3 \%)$, and mastitis $(25.7 \%)$ were selected most frequently. Producers were also asked to score the same list of parameters on usefulness using a 5-point scale $(1=$ not useful and $5=$ useful $)$. Producers indicated (mean $\pm \mathrm{SE}$ ) mastitis $(4.77 \pm 0.47)$, standing estrus $(4.75 \pm 0.55)$, and daily milk yield $(4.72 \pm 0.62)$ to be most useful. Producers were asked to score considerations taken before deciding to purchase a precision dairy farming technology from a predetermined list $(1=$ not important and $5=$ important). Producers indicated benefit-to-cost ratio $(4.57 \pm 0.66)$, total investment cost (4.28 \pm 0.83$)$, and simplicity and ease of use (4.26 $\pm 0.75)$ to be most important when deciding whether to implement a technology. Producers were categorized based on technology use (using technology vs. not using technology) and differed significantly across technology usefulness scores, daily milk yield (using technologies: $4.83 \pm 0.07$ vs. not using technologies: $4.50 \pm 0.10$ ), and standing estrus (using technologies: $4.68 \pm 0.06$ vs. not using technologies: $4.91 \pm 0.09$ ). The same categories were used to evaluate technology use effect on prepurchase technology selection criteria and availability of local support (using technologies: $4.25 \pm 0.11$ vs. not using technologies: $3.82 \pm 0.16$ ) differed significantly. Producer perception of technology remains relatively unknown to manufacturers. Using this data, technology manufacturers may better design and market technologies to producer need.
\end{abstract}

Received October 12, 2014.

Accepted March 12, 2015.

${ }^{1}$ Corresponding author: jbewley@uky.edu
Key words: producer perception, survey, parameter, precision dairy farming technology

\section{INTRODUCTION}

Precision dairy farming has been defined as, "the use of information and communication technologies for improved control of fine-scale animal and physical resource variability to optimize economic, social, and environmental dairy farm performance" (Eastwood et al., 2012). Parameters monitored by these technologies include daily milk yield, milk components, step number, temperature (in various places and forms on and within the cow), milk conductivity, automatic estrus-detection monitors, and daily BW measurements (Bewley, 2010). In addition to the parameters already monitored, many other parameters have also been proposed. Proposed parameters include jaw movements, ruminal $\mathrm{pH}$, reticular contractions, heart rate, animal positioning and activity, vaginal mucus electrical resistance, feeding behavior, lying behavior, odor, glucose, acoustics, progesterone, individual milk components, color (as an indicator of cleanliness), infrared udder surface temperatures, and respiration rates (Bewley, 2010). Through the use of precision dairy farming technologies, producers strive to improve farm performance. Technology use becomes important as dairy farmers refine their management practices with emphasis on farm efficiency (El-Osta and Morehart, 2000).

The decision to purchase and implement a precision dairy technology represents a significant investment for a producer, who often faces the challenge of choosing a technology that will serve their needs for several years. Dairy producers tend to plan for the long-term consequences of their decisions, mapping responses to a series of long-term occurrences (Boehlje and Schiek, 1998), and in making decisions must account for many different factors, such as financial scale, demographic, and other considerations (Khanal et al., 2010). The effect of an unproductive investment could be severely detrimental to a dairy farmer and, accordingly, investments are approached with caution. In contrast, decisions may not always be as predictable, as advice and direction is drawn from many sources 
in making management decisions. Trained professionals (i.e., veterinarians, nutritionists, consultants, extension specialists, and so on), family members, other dairy farmers, written publications, and even gut feeling may be considered in the decision-making process (Russell and Bewley, 2013).

As precision dairy farming technologies have evolved, new parameters and monitoring methods have been created. As a result, dairy farmers encounter many choices in the type of precision dairy farming technology they may implement and many dairy farmers are simply unaware of the technologies currently available to them (Russell and Bewley, 2013). Systems are available for monitoring animal activity, rumination, resting time, temperature, and many other events associated with animal well-being (Nebel, 2013), but little is understood concerning producer technology adoption, perception of individual technologies, or opinion of the parameters they measure. Gathered information is limited to technologies used in or around dairy parlors (Jago et al., 2013). Producers implementing technologies experience increased financial opportunity, and understanding the process by which producers become aware of and adopt new technologies is of interest to the private sector, researchers, and policymakers alike (Pierce and Nowak, 1999; Daberkow and McBride, 2003). This contrasts the current trend in precision dairy farming where, despite being the end users, dairy farmers are typically excluded from technology development (Huirne et al., 1997). As a result, technologies may not fulfill on-farm needs, keeping technology adoption relatively low (Huirne et al., 1997; Gelb et al., 2001). The objectives of the current study were to identify the parameters currently measured on farms, find the considerations a farmer takes when selecting precision dairy farming technologies, and determine the parameters perceived by producers as most useful.

\section{MATERIALS AND METHODS}

In March 2013, an 8-question survey was created made available through SurveyMonkey (SurveyMonkey Inc., Palo Alto, CA). Online methods were chosen to reach the maximum number of respondents across a wide population of dairy farmers. A test survey was made and links were sent to extension specialists and producers $(\mathrm{n}=5)$. Appropriate revisions were made based on test survey respondent feedback regarding survey content and organization. Following revision, the survey was made accessible to the general public for 2 mo. Dairy producers were identified as the target audience of this survey, with no specific conditions being specified for respondents to be eligible to complete the survey. The survey was sent to potential respon- dents through uniform resource locator (URL) links distributed by dairy-related email list serves, as well as internet publications and print magazines volunteering to distribute the URL.

Electronic methods of URL distribution were the preferred medium of distribution because respondents had the ability to click on the actual URL, taking them directly to the survey. Respondents seeing the URL in print had to copy the address and enter it directly into their web browser to access the survey, so the electronic method was thought to be easier for the respondent. The survey consisted of 7 close-ended questions. Additionally, 1 open-ended question in which respondents could express their thoughts, suggestions, and opinions was included. Responses to the open-ended question were not included in analysis, but relevant responses were included within results.

Respondents were asked to disclose the country and state or province where their farm was located (question 1), their age (question 2), their current herd size (including dry cows; question 3), and their role on the farm (question 4). Age and farm role were presented to respondents in categories, whereas country and state or province and herd size required users to input values. Age categories were predefined at $<30,30$ to 40,41 to 50,51 to 60 , and $>60$. Five options for on-farm role were provided to respondents: (1) owner, co-owner, or partner; (2) president or vice president; (3) manager, supervisor, or herdsman; (4) general employee; or (5) other. Respondents indicating roles outside of an onfarm role or a directly related title were excluded from further analysis. Additionally, respondents were asked to identify the parameters currently measured on their farm by precision dairy farming technologies from a predetermined list (question 5; Table 1). Parameters from the predetermined list were generated from previous literature (Bewley, 2010), producer input, and from the input of extension specialists. Parameters used to determine the general health of the mammary system were combined into the mastitis option within this survey, as they were considered potentially confusing. One option within the list allowed farmers to answer "not applicable" if they did not currently use technologies on their farm. Depending on the answer to this question, producers were sorted into one of 2 categories: (1) producers using technologies or (2) producers not using technologies.

A Likert (1932) scale assigned numerical values to the responses of the final 2 questions. Producers were asked to score considerations made in deciding to purchase precision dairy farming technologies from a predetermined list (question 6; Table 2) similar to that used by Russell and Bewley (2013). Additions and modifications were made to the list in the same method as parameters 
Table 1. Results from a producer-based survey showing percentages of surveyed producers using technologies to measure various parameters ${ }^{1}$

\begin{tabular}{lc}
\hline & $\begin{array}{c}\text { Respondent } \\
\text { percentage } \\
(\mathrm{n}=109)\end{array}$ \\
Parameter & 52.3 \\
\hline Daily milk yield & 41.3 \\
Cow activity & 25.7 \\
Mastitis & 24.8 \\
Milk components (e.g., fat, protein, and SCC) & 21.1 \\
Standing estrus & 12.8 \\
Feeding behavior & 12.8 \\
Temperature & 11.0 \\
BW & 10.1 \\
Rumination & 9.2 \\
Rumen activity & 8.3 \\
Animal position and location & 8.3 \\
Lying and standing behavior & 7.3 \\
Jaw movement and chewing activity & 6.4 \\
Hoof health & 4.6 \\
Lameness & 3.7 \\
Heart rate & 2.8 \\
BCS & 1.8 \\
Methane emissions & 1.8 \\
Respiration rate & 0.9 \\
Rumen pH &
\end{tabular}

${ }^{1}$ These parameters were presented to respondents in a predetermined list.

${ }^{2}$ Parameters associated with mastitis detection were combined due to the highly technical and variable nature of these parameters.

in Table 1. Each score was assigned a numerical value, with $1=$ unimportant, $2=$ of little importance, $3=$ moderately important, $4=$ somewhat important, and 5 $=$ important. Producers were also asked to classify parameters, based on usefulness, from the same list used in the technology adoption question (question 7; Table 3 ). Each score was assigned a numerical value, with 1 $=$ not useful, $2=$ of little usefulness, $3=$ moderately useful, $4=$ somewhat useful, and $5=$ useful.

Statistical analyses were conducted on completed surveys using SAS Version 9.3 (SAS Institute Inc., Cary, NC). Median herd size (lactating and dry) was calculated using the MEANS procedure. Least squares means were calculated using the GLM procedure across age, herd size, and technology usage categories, on scored parameter usefulness and prepurchase considerations. Chi-squared analyses were performed using the FREQ procedure to compare differences in producer age, and herd size categories across all parameters currently measured on respondents' farms.

\section{RESULTS AND DISCUSSION}

One objective of our survey design was to increase response numbers by decreasing survey length, as a smaller survey may increase the total number of responses (Deutskens et al., 2004). Following survey closure, 43 of the 152 surveys collected were removed

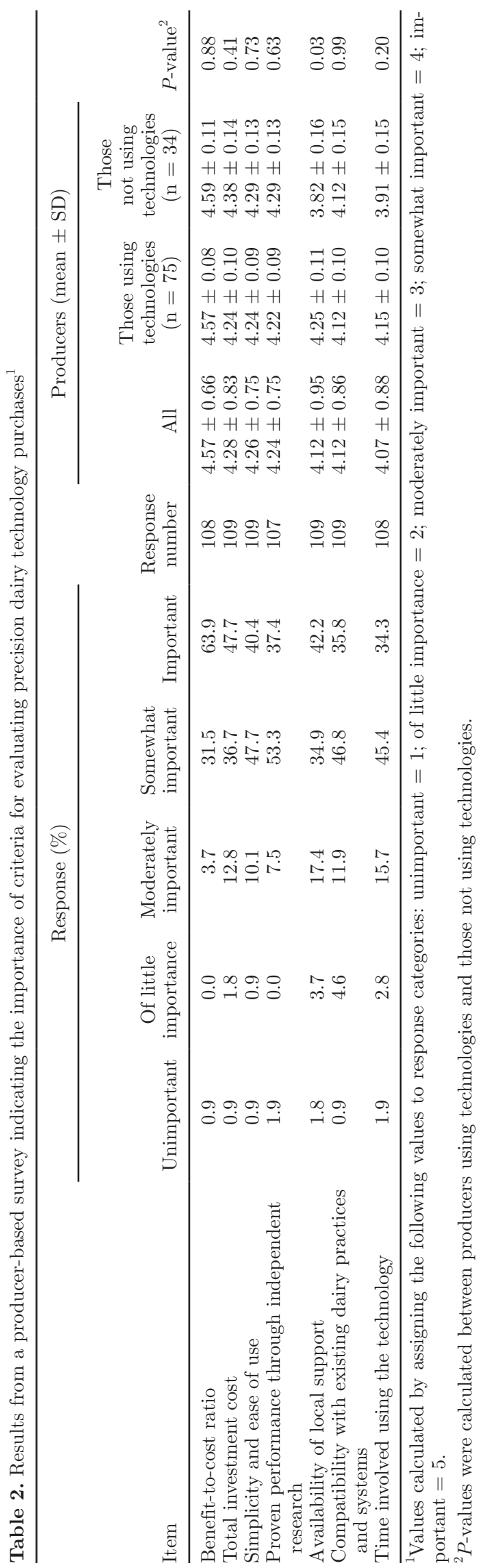




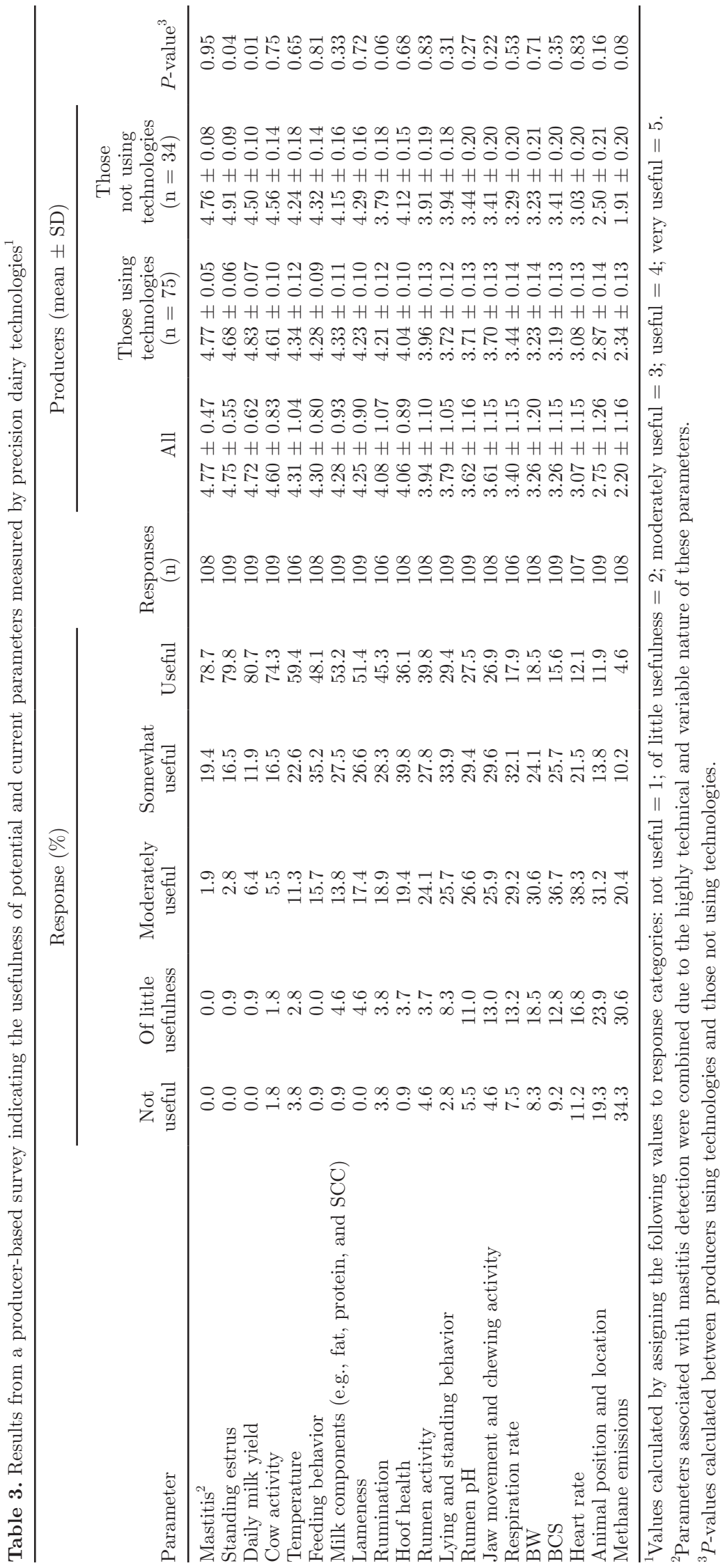


due to incompletion or error. Surveys were considered incomplete or erroneous if more than $75 \%$ of questions were left unanswered or the role on-farm was anything other someone directly employed on the farm. Incomplete and erroneous responses were removed from the sample and further analysis. In the data analysis, 109 complete responses were used.

Country and state of farm location (question 1) answers were excluded from further analysis because sample sizes were insufficiently large to compare. Respondent ages by category were $<30(17.4 \%), 30$ to $40(28.4 \%), 41$ to $50(25.7 \%), 51$ to $60(20.2 \%),>60$ $(8.3 \%)$. Producer age results are indicative of a sample that is younger than expected, with most dairy producer in the United States being between 45 and 54 (Vilsack and Clark, 2014). Median herd size was 230 cows (lactating and dry). Herd size categories were generated based on quartile and were $<110(26.6 \%)$, 111 to 230 (24.8\%), 231 to $573(23.9 \%),>574(24.8 \%)$. In a report by NAHMS (2007), herds with fewer than 100 animals were categorized as small, medium with sizes between 100 and 499 animals, and large with 500 or more animals. The NAHMS (2007) report and the 2012 Census of Agriculture (Vilsack and Clark, 2014) may not be representative of all countries; however, the majority of respondents in the current study were from the United States and findings were in congruence. Producer categories, generated based on respondents' role on the farm, were (1) owner, co-owner, or partner $=72.5 \%$; (2) president or vice president $=1.8 \%$; (3) manager, supervisor, or herdsman $=23.9 \%$; and $(4)$ general employee $=1.8 \%$. An "other" category was provided and respondents were asked to specify their role. Surveys with responses in the "other" category were removed because none were on-farm employees. Because of the high amount of respondents being in the first category, role on the farm was not considered as an explanatory factor in further analyses.

\section{Technology Use}

Results of parameters currently measured by precision dairy farming technologies on dairy farms are presented in Table 1. Producers were able to select multiple parameters to account for producers using multiple technologies or in some cases a single technology measuring several parameters (e.g., measuring milk yield and electrical conductivity for mastitis detection). Additionally, the potential exists for producers to have more than one technology. Producer responses indicated that the most commonly measured parameters by already adopted technologies were daily milk yield $(52.3 \%)$, cow activity (41.3\%), mastitis $(25.7 \%)$, and milk components $(24.8 \%)$. Use of these parameters was consistent with individual parameter age and commercial availability to producers. Cow activity is one of the oldest parameters used in dairy cattle monitoring and was first characterized using technologies by Farris (1954). In addition, parameters such as milk yield and SCC, although not automatic, have been available to producers through the National Dairy Herd Information Association (Verona, WI) and other similar organizations for many years. Due to producer familiarity with these parameters and those similar to them, use may be higher, especially when compared with the newer parameters with which producers are less likely to be familiar. The least-used technologies were rumen $\mathrm{pH}(0.9 \%)$, respiration rate $(1.8 \%)$, methane emissions $(1.8 \%)$, and BCS $(2.8 \%)$. These parameters were expected to be less used as they are not as commercially available as others are. Producers using these technologies may have been associated with research institutions, as commercial use of these parameters is sparse.

\section{Criteria Considered in Purchasing Decisions}

Results of criteria considered in purchasing precision dairy farming technologies on dairy farms are presented in Table 2. When asked to score criteria on importance when making purchasing decisions regarding precision dairy farming technologies, producers indicated benefitto-cost ratio as most important $(4.57 \pm 0.66)$, followed by total investment cost $(4.28 \pm 0.83)$, simplicity and ease of use (4.26 \pm 0.75$)$, proven performance through independent research $(4.24 \pm 0.75)$, and availability of local support (4.12 \pm 0.95 ; Table 2). To correspond with these findings, many producer comments from the open-ended questions indicated similar thoughts:

- "They (technologies) must be affordable."

- "Make it profitable and cost effective for small farms."

- "They're hard to afford for a small farm."

- "Need proven payback in order to invest. It's easy to be overwhelmed with additional information that, while interesting, doesn't improve cow comfort or profitability."

- "We are small enough that most can be and are simply observed."

- "Durability of devices is important. This is related to ease of use and cost/benefit."

Results indicate that technologies must have a high benefit-to-cost ratio. Many responses also indicated labor alternatives to be more realistic, especially on small farms. Similar results were observed by Russell and Bewley (2013) in a study of Kentucky dairy producers, where producers indicated an undesirable 
cost-to-benefit ratio, lack of perceived economic value, difficulty or complexity of use, and poor technical support or training as influential on technology adoption. Producers found all considerations in this question to be important for evaluating precision dairy farming technology purchases, as all of the criteria scored above 4 when the maximum selectable value was 5 .

Open-ended question responses also identified data integration and use producer concerns. For example, "The ability to tie various technologies together on a common platform/herd health suite is necessary to limit redundancy and the need to enter data twice. The ability to open multiple modules simultaneously is also necessary, especially for those that run extended desktops with 3 or more monitors." Yule and Eastwood (2012) expressed similar findings of precision dairy farming technology data integration being a concern for producers. This could be because many of the current technologies require data to be entered separately from dairy herd management software if used in conjunction.

\section{Parameter Usefulness}

The perceived usefulness of individual technologies by producers is presented in Table 3 . Producers indicated the most useful parameters to be mastitis (mean $\pm \mathrm{SD} ; 4.77 \pm 0.47)$, standing estrus $(4.75 \pm 0.55)$, daily milk yield (4.72 \pm 0.62$)$, cow activity $(4.60 \pm 0.83)$, and temperature $(4.31 \pm 1.04)$. Producers indicated BW $(3.26 \pm 1.20)$, BCS $(3.26 \pm 1.15)$, heart rate $(3.07 \pm$ $1.15)$, animal position and location $(2.75 \pm 1.26)$, and methane emissions $(2.20 \pm 1.16)$ to be the least useful.

Producer interest may not be in congruence with biological meaningfulness for many parameters. One such parameter was BCS. Regular assessment of the amount of body fat mobilized during early lactation and restored during mid and late lactation by dairy cows can aid in adjusting the feeding strategy to meet actual requirements of dairy cows more closely (Gallo et al., 1996). Such a technology may prove useful for producers, but producer perception was relatively poor for the current study. One reason for the findings in our survey could be the lack of commercially available systems scoring body condition and other parameters. Methods have been described with which to automatically monitor BCS by Coffey et al. (2003) and Bewley et al. (2008), but few technologies monitoring this parameter are commercially available at this time. Another reason for this trend may be the perception of BCS as a whole. This perception may not come from a lack of perceived usefulness, but a lack of practicality in a commercial setting. The commitment of skilled labor to undertake routine manual BCS assessment is not always possible (Roche et al., 2009), which may lead to producers negatively perceiving this parameter. The combination of poor perception, lack of practicality, and lack of commercially available systems may be the reason for multiple poorly perceived parameters in the current study.

Producers indicated the automatic detection of standing estrus to be one of the most useful parameters. One explanation for the highly perceived usefulness of this parameter is that it could be confused with other parameters often associated with estrus detection, such as cow activity. Another explanation is that producers are more familiar with visual estrus-detection techniques and may be more likely to perceive a technology that does this automatically as very useful. Methods of monitoring mounting events have been described (Senger, 1994), but few commercially available technologies monitor tangible standing estrus or mounting events, especially when compared with cow activity.

In the open-ended response question, several producers also indicated technologies they viewed as potentially useful. These suggestions could provide useful input in the development of future technologies:

- "A technology to predict risk of lameness within a system or for individual cows would be helpful."

- "A feed consumption monitor for individual cow TMR intake."

- "Calving detection by correlating rumination and activity with calving onset would make monitoring a just-in-time calving arrangement easier."

\section{Statistical Comparisons}

Least squares means were calculated on producer prepurchase considerations and parameter usefulness across age, herd size, and region categories, with no significant results being found $(P \geq 0.05)$; however, technology adopters and technology nonadopters differed in prepurchase consideration importance and perceived parameter usefulness. Availability of local support was more important to producers already using technologies $(4.25 \pm 0.11)$ than those that were not (3.82 $\pm 0.16 ; P=0.03$; Table 2). Russell and Bewley (2013) established that producers value adequate technical support and training and that this was important in their decision-making. The findings of the current study are consistent with this, adding that producers currently using technologies may be familiar with the problems, questions, and troubleshooting associated with technology implementation. These experiences may lead producers already using technologies to place more value on technical support when purchasing technologies. Technology manufacturers should consider these findings to increase customer satisfaction. Pro- 
ducers may not only need assistance with technologies following adoption, but consistently after.

Respondent perception of parameter usefulness also differed across technology use categories (Table 3). Milk yield was considered more useful by producers currently using technologies $(4.83 \pm 0.07)$ than those not using technologies $(4.50 \pm 0.10 ; P=0.01)$, and standing estrus was perceived to be significantly less useful by producers using technologies $(4.68 \pm 0.06)$ versus those not using technologies $(4.91 \pm 0.09 ; P=$ 0.04). Both categories of producer regarded these parameters to be relatively useful because both producer categories scored milk yield and standing estrus above 4. The automated measuring of milk yield can be used to identify sick animals in dairy herds (Deluyker et al., 1991; Mottram, 1997), identify high-producing cattle with greater nutritional needs (Clark and Davis, 1980), or identify low-producing cows for culling (Bascom and Young, 1998). Producers already using this technology may see the increased benefit of monitoring this parameter in their herds. Automated measures of cow activity can identify cattle in estrus without the necessity of observing an event where a cow stands to be mounted (Farris, 1954; Kiddy, 1977). Producers currently using technology may be familiar with this knowledge and, as a result, perceive standing estrus as being less important.

\section{Potential Bias}

Bias may be present in this survey and the means by which our survey was distributed may be to blame. Email, electronic publication, and written publications served as the medium of distribution for the survey, so only producers receiving the aforementioned materials would have access to the survey. Producers using email and electronic publications to gather and interpret information regarding their farm may have been more likely to access this web-based survey. Farmers not utilizing these methods would be less likely to receive the survey or access it from a link provided in a written publication. As a consequence, the sample may not have been completely representative of the entire population of dairy producers; however, producers not using technology or computers would be less likely to implement these technologies (Daberkow and McBride, 1998). The sample of producers in our study may be more representative of the population of producers willing and able to implement technologies, but further research may be necessary to definitively corroborate the findings of our study. Results of the current study show the potential for mounting monitors to be highly utilized by producers, but these results should be approached with caution.

\section{Technology Confidence and Use}

When considering precision dairy farming technologies, producers consider how the technology fits in their operation and what it will accomplish (Yule and Eastwood, 2012). There is a need for manufacturers to consider the end use of these technologies in development, testing, and marketing to demonstrate technology usefulness in a commercial setting to inspire producer confidence (Wathes et al., 2008). Technology performance also must be evaluated. Objective information regarding technology efficacy would also allow dairy farmers to make better educated decisions on individual technologies, and lead to improved technologies through competition between rival manufacturers (Jago et al., 2013). There is also a need for organizations to train producers to effectively use these technologies and interpret the information generated from them (Jago et al., 2013). Perhaps after manufacturers identify parameters on which dairy farmers need informed or parameters producers most value, manufacturers can more effectively serve the needs of dairy producers.

\section{CONCLUSIONS}

Technologies monitoring milking performance, reproductive performance, and udder health were the most widely used among current parameters. Parameter usefulness perception was highest for technologies monitoring mastitis, estrus, and milk yield parameters. These findings are indicative of producers best perceiving and mostly adopting technologies monitoring cow health and performance, as well as reproductive status. Many producers did not use technologies and could provide potential areas for manufacturers to expand their marketing and sales. Additionally, producers find factors associated with return on investment, total investment, and technology performance as the most important prepurchase considerations when deciding whether to implement a technology. Producers currently using technologies value the availability of local support more than those not using technologies, meaning dairy farmers using technologies may be more familiar with the requirements of implementing a technology. The information in this study may allow technology manufacturers to better inform producers, market technologies, and develop parameters that are more useful to producers.

\section{ACKNOWLEDGMENTS}

The authors thank the dairy producers who participated in this survey and those who edited or contributed to it. Additionally, Karmella Dolecheck, Barabara 
Wadsworth, Amanda Stone, I-Ching Tsai, Derek Nolan, Maegan Weatherly, Lauren Mayo, and Elizabeth Ecklekamp (University of Kentucky) deserve special thanks for their assistance with this paper.

\section{REFERENCES}

Bascom, S. S., and A. J. Young. 1998. A summary of the reasons why farmers cull cows. J. Dairy Sci. 81:2299-2305.

Bewley, J. 2010. Precision dairy farming: Advanced analysis solutions for future profitability. Pages $2-5$ in Proc. 1st North Am. Conf. Precis. Dairy Manag. Toronto, Canada. Progressive Dairy Operators, Guelph, ON, Canada.

Bewley, J. M., A. M. Peacock, O. Lewis, R. E. Boyce, D. J. Roberts, M. P. Coffey, S. J. Kenyon, and M. M. Schutz. 2008. Potential for estimation of body condition scores in dairy cattle from digital images. J. Dairy Sci. 91:3439-3453.

Boehlje, M., and W. Schiek. 1998. Critical success factors in a competitive dairy market. J. Dairy Sci. 81:1753-1761.

Clark, J. H., and C. L. Davis. 1980. Some aspects of feeding high producing dairy-cows. J. Dairy Sci. 63:873-885.

Coffey, M., N. McFarlane, and T. Mottram. 2003. The feasibility of automatic condition scoring. Holstein J. 66:82-83.

Daberkow, S., and W. McBride. 2003. Farm and operator characteristics affecting the awareness and adoption of precision agriculture technologies in the US. Precis. Agric. 4:163-177.

Daberkow, S. G., and W. D. McBride. 1998. Socioeconomic profiles of early adopters of precision agriculture technologies. J. Agribus. $16: 151-168$

Deluyker, H. A., J. M. Gay, L. D. Weaver, and A. S. Azari. 1991. Change of milk yield with clinical diseases for a high producing dairy herd. J. Dairy Sci. 74:436-445.

Deutskens, E., K. De Ruyter, M. Wetzels, and P. Oosterveld. 2004. Response rate and response quality of internet-based surveys: An experimental study. Mark. Lett. 15:21-36.

Eastwood, C. R., D. F. Chapman, and M. S. Paine. 2012. Networks of practice for co-construction of agricultural decision support systems: Case studies of precision dairy farms in Australia. Agric. Syst. 108:10-18.

El-Osta, H. S., and M. J. Morehart. 2000. Technology adoption and its impact on production performance of dairy operations. Rev. Ag. Econ. 22:477-498.

Farris, E. J. 1954. Activity of dairy cows during estrus. J. Am. Vet. Med. Assoc. 125:117-120.

Gallo, L., P. Carnier, M. Cassandro, R. Mantovani, L. Bailoni, B. Contiero, and G. Bittante. 1996. Change in body condition score of holstein cows as affected by parity and mature equivalent milk yield. J. Dairy Sci. 79:1009-1015.

Gelb, E., C. Parker, P. Wagner, and K. Rosskopf. 2001. Why is the ICT adoption rate by farmers still so slow? Pages 40-48 in Proc. ICAST, Vol. VI. Int. Conf. Agric. Sci. Technol. (ICAST), Beijing, China.

Huirne, R. B. M., S. B. Harsh, and A. A. Dijkhuizen. 1997. Critical success factors and information needs on dairy farms: The farmer's opinion. Livest. Prod. Sci. 48:229-238.

Jago, J., C. Eastwood, K. Kerrisk, and I. Yule. 2013. Precision dairy farming in Australasia: Adoption, risks and opportunities. Anim. Prod. Sci. 53:907-916.

Khanal, A. R., J. Gillespie, and J. MacDonald. 2010. Adoption of technology, management practices, and production systems in us milk production. J. Dairy Sci. 93:6012-6022.

Kiddy, C. A. 1977. Variation in physical-activity as an indication of estrus in dairy-cows. J. Dairy Sci. 60:235-243.

Likert, R. 1932. A technique for the measurement of attitudes. Arch. Psychol. 22:1-55.

Mottram, T. 1997. Automatic monitoring of the health and metabolic status of dairy cows. Livest. Prod. Sci. 48:209-217.

NAHMS. 2007. Facility characteristics and cow comfort on U.S. Dairy operations. USDA:APHIS:VS, CEAH, National Animal Health Monitoring Systems, Fort Collins, CO.

Nebel, R. 2013. Attaining reproductive solutions through activity and health monitoring. Pages 75-80 in Proc. 2013 Precis. Dairy Conf. Expo, Rochester, MN. University of Minnesota, Minneapolis.

Pierce, F. J., and P. Nowak. 1999. Aspects of precision agriculture. Adv. Agron. 67:1-85.

Roche, J. R., N. C. Friggens, J. K. Kay, M. W. Fisher, K. J. Stafford, and D. P. Berry. 2009. Invited review: Body condition score and its association with dairy cow productivity, health, and welfare. J. Dairy Sci. 92:5769-5801.

Russell, R. A., and J. M. Bewley. 2013. Characterization of Kentucky dairy producer decision-making behavior. J. Dairy Sci. 96:47514758.

Senger, P. L. 1994. The estrus detection problem: New concepts, technologies, and possibilities. J. Dairy Sci. 77:2745-2753.

Vilsack, T., and C. Z. Clark. 2014. USDA report AC-12-A-PR. National Agricultural Service, Washington, DC.

Wathes, C. M., H. H. Kristensen, J. M. Aerts, and D. Berckmans. 2008. Is precision livestock farming an engineer's daydream or nightmare, an animal's friend or foe, and a farmer's panacea or pitfall? Comput. Electron. Agric. 64:2-10.

Yule, I., and C. Eastwood. 2012. Challenges and opportunities for precision dairy farming in New Zealand. Pages 15-18 in Proc. 11th Int. Conf. Precis. Ag., Indianapolis, IN. J. Stafford, ed. 